\title{
Effects of lateral and medial septal lesions on response suppression maintained by response- contingent and response-independent shock
}

\author{
J. FELDON, J. N. P. RAWLINS, and J. A. GRAY \\ University of Oxford, Oxford, England
}

\begin{abstract}
Rats with electrolytic lesions in the medial (MS) or lateral (LS) septal areas were allocated to groups on electrophysiological criteria (loss or persistence of hippocampal theta rhythm, respectively) subject to subsequent histological checking. They were trained to press a lever for sucrose reward on a random interval (RI) schedule and while leverpressing were presented with two stimuli, each associated with a different schedule of shock delivery: in the presence of one, shocks occurred on an RI schedule irrespective of the rat's behavior; in the presence of the other, shocks were programmed by the same schedule but delivered only when the rat pressed the lever. Both stimuli suppressed leverpressing. MS, but not LS, lesions significantly increased baseline RI responding; LS, but not MS, lesions significantly disinhibited responding suppressed by signaled shock, whether or not the shock was response-contingent. These changes were related to the effects of MS and LS lesions on hippocampal theta.
\end{abstract}

There are a number of reports that large lesions of the anterior septal area impair the rat's ability to withhold instrumental responses when these are punished (Dickinson, 1974; Lubar \& Numan, 1973) and some evidence that this effect is due in particular to damage to the lateral septal nuclei (Hamilton, Kelsey, \& Grossman, 1970; McGowan, Hankins, \& Garcia, 1972). In contrast, the results of studies of on-thebaseline conditioned suppression (that is, with shock independent of responding rather than responsecontingent, as in punishment) have been equivocal. Neither Duncan (1972) nor Molino (1975) found any effect of septal lesions using this paradigm. Brady and Nauta (1955) did find a deficit in response suppression, but only at 3 days postoperatively; at 60 postoperative days, septal lesions had no effect. Harvey, Lints, Jacobson, and Hunt (1965) also found a deficit, but only with 1-mA shock (not with $.5 \mathrm{~mA}$ ). The most convincing demonstration of an effect of septal lesions on conditioned suppression has come from Dickinson (1975), who explicitly compared conditioned suppression and punishmentproduced suppression in septal animals, finding an equal alleviation by the lesion in the two cases.

This research was supported by the Medical Research Council. J. N. P. Rawlins is a Weir Research Fellow at University College, Oxford. J. Feldon, who is now with the Department of Psychology, Tel-Aviv University, Israel, held the Kenneth Lindsay Scholarship awarded by the Anglo-Israel Association. We are grateful to J. C. Leslie for help in designing the experiments, F. H. C. Marriot for help with statistical problems, and A. Ridgers and N. McNaughton for help with computing. Requests for reprints should be sent to: J. A. Gray, Department of Experimental Psychology, South Parks Road, Oxford, OX1 3UD, England.
Dickinson's (1975) lesions affected the entire anterior septal area. In the present experiment, we reexamined the role of the lateral and medial septal areas in the two kinds of response suppression, using a within-animal design in which different stimuli signal response-contingent and response-independent shock (Rawlins, Feldon, \& Gray, 1980).

At the same time, we evaluated the role played by the hippocampal theta rhythm in the effects which septal lesions produce on response suppression. The pacemaker cells which control the theta rhythm are located in the medial septal area (Apostol \& Creutzfeldt, 1974; Stumpf, 1965); lesions in the medial septal area abolish the theta rhythm, while lesions in the dorsolateral septal area do not (Rawlins, Feldon, \& Gray, 1979). Recordings of hippocampal electrical activity were made in all the subjects both before and after their lesions were made. The changes in the theta activity produced by the lesions could thus be compared with the behavioral changes produced.

Previous experiments investigating persistence in the extinction of a food-reinforced running response have shown that medial septal lesions increase persistence, while lateral septal lesions do not (Feldon \& Gray, 1979a, 1979b). If the behavioral inhibition produced by signals of nonreward is mediated by the same brain system as inhibition produced by signals of punishment (Gray, 1967; Wagner, 1966), then only medial septal lesions abolishing the theta rhythm should increase punished responding; lateral septal lesions which leave theta intact should leave punished behavior unaltered. As noted above, existing data are inconsistent with this prediction. 


\section{METHODS}

\section{Surgery and Electrophysiology}

All surgical, electrophysiological, and histological procedures have been fully described by Rawlins et al. (1979). An initial total of 55 naive male Wistar rats were implanted with electrodes in the septal area (used both for stimulation and lesioning) and with recording electrodes bilaterally in the dorsomedial subiculum (James, McNaughton, Rawlins, Feldon, \& Gray, 1977). Of these, 30 had a single bipolar electrode aimed at the medial septal area and 25 had two bilateral monopolar electrodes aimed at the lateral septal area. The electrodes were led out to an Amphenol plug and secured to the skull with dental cement and stainless steel screws. The operations were performed on a Kopf stereotaxic instrument after anesthesia with a mixture $(3 \mathrm{ml} / \mathrm{kg})$ containing $9.7 \mathrm{mg} / \mathrm{ml}$ sodium pentobarbital and $42 \mathrm{mg} / \mathrm{ml}$ chloral hydrate. After operation, all subjects were caged individually.

A minimum of 1 week after the operation, recordings of spontaneous hippocampal electrical activity were taken while the animal was in an open-topped box $(30 \times 30 \times 35 \mathrm{~cm})$. At the same time, hippocampal responses to electrical stimulation of the septal area were recorded. Animals with medial septal electrodes were selected for the medial septal lesion group if clear hippocampal theta could be elicited by septal stimulation at relatively low threshold currents; four rats in which the threshold was greater than $300 \mu \mathrm{A}$ were allocated to the operated control (OC) group. For allocation to the lateral septal lesion group, the requirements were that (1) stimulation applied across the two septal electrodes should produce a clear response in the hippocampus, (2) the threshold current to provoke this response ipsilaterally to the cathode was approximately equal in both hemispheres, and (3) the threshold current ipsilateral to the cathode was close to but less than the contralateral threshold. These requirements were intended to ensure symmetrical placement of the lateral septal electrodes. Four animals not meeting them were allocated to the $O C$ group.

The lesions were produced under ether anesthesia by dc current from a constant-current source passed through septal electrodes. For the medial septal lesions, $1 \mathrm{~mA}$ was passed for $15 \mathrm{sec}$, using as anode the medial septal electrode and as cathode a clip on the rat's ear. For the lateral septal lesions, $1 \mathrm{~mA}$ was similarly passed for $15 \mathrm{sec}$ through each of the two lateral septal electrodes in turn. Rats in the OC group were anethetized only.

A minimum of 1 week after making the lesions, recordings of spontaneous hippocampal activity were again taken, as before. The amplitudes of theta activity (recorded on a Grass $79 \mathrm{D}$ polygraph) before and after the lesion were measured, and the percentage retention of theta was calculated (Rawlins, Feldon, \& Gray, 1979). At this stage, the subjects were reallocated to the final experimental groups as follows:

Subjects with low theta retention following medial septal lesions were placed in the "medial septal" (MS) group $(n=8)$. One subject in this group had $30 \%$ theta retention in the right hippocampus, but a complete loss of theta in the left. All other subjects had total theta losses in both hemispheres.

Subjects with medial septal lesions and high theta retention were placed in the "failed medial" (FM) group $(n=4)$. All had approximately $100 \%$ theta retention.

Subjects with lateral septal lesions and with high theta retention $>60 \%)$ were placed in the "lateral septal" (LS) group $(n=8)$.

Subjects with lateral septal lesions and with low theta retention were placed in the "failed lateral" $(F L)$ group $(n=4)$. All had total theta loss in both hemispheres.

\section{Histology}

At the conclusion of the behavioral experiment, all subjects were given an overdose of pentobarbitone and perfused through the heart with saline and then $10 \%$ formol saline. The brains were sectioned, stained, and examined microscopically.

\section{Procedure}

The behavioral methods were as described by Rawlins et al. (1980, Experiment 2). The experiments were run in four Campden
Instruments CI 460 Skinner boxes, each in a sound-attenuating case, with consequences programmed for only the left-hand lever. Each session lasted $55 \mathrm{~min}$; throughout the session the light above the left lever was on. The experiments were controlled by a NOVA 800 computer programmed in ACT-N (Millenson, 1971).

The animals were trained to leverpress for $.1 \mathrm{ml}$ of $10 \%$ sucrose on a random-interval (RI) 64-sec reinforcement schedule, and then (after 22 sessions on this baseline schedule) introduced to both response-independent and response-contingent shock. This required two kinds of "intrusion" period: in both of them, an independent RI 64-sec schedule programmed .5-sec shock (applied to the grid floor from Grason-Stadler scrambled shock generators). In one kind of intrusion period (the "conditioned suppression", component), a shock was delivered immediately after it was programmed. In the second (the "punishment" component), a programmed shock was delivered when the animal next pressed the lever. The next random interval was timed in both cases from shock delivery. If, in the punishment component, no response had been made between the programming of the shock and the ending of the intrusion period, no shock was delivered. During each session, two punishment and two conditioned suppression components occurred. Both the order and the time of onset of these components were varied from session to session although the first intrusion period was at least $11 \mathrm{~min}$ from the start of the session. The two kinds of intrusion period were signaled by different stimuli, $S_{c}$ (signaling conditioned repression: i.e., response-independent shock) and $S_{p}$ (signaling punishment: i.e., response-contingent shock). The stimuli used (the overhead houselight and a tone) were chosen so as to be spatially diffuse, thus minimizing the possibility that any changes produced by the lesions in spatial ability (O'Keefe \& Black, 1978; Winson, 1978) might affect the results. For half the animals in each group, $S_{c}$ consisted of the houselight flashing at $4 \mathrm{~Hz}$ and $\mathrm{S}_{\mathrm{p}}$ consisted of the houselight being steadily on combined with an $850-\mathrm{Hz}$ tone, interrupted at $4 \mathrm{~Hz}$, which raised the sound level in the Skinner box by about 1.5 dB. For the other half, the significance of these two stimuli was reversed. Animals were run in squads of four, there being one MS, one LS, one OC, and either one FM or one FL subject in each squad.

The experiment was divided into two phases.

Phase 1. The first 24 sessions were run with identical shock levels for all subjects: $.2 \mathrm{~mA}$ for 5 sessions, then $.25 \mathrm{~mA}$ for 12 sessions, and finally $.3 \mathrm{~mA}$ for 7 sessions. The small increments in shock intensity were selected so as to minimize the disruption of baseline responding. The shock duration was maintained at $.5 \mathrm{sec}$. The data from one session were lost.

Phase 2. Over the next 96 sessions, shock intensity was adjusted individually for each animal so as to produce equal suppression ratios. These were calculated as $A /(A+B)$, where $A=$ number of responses in a 3-min intrusion period and $B=$ number of responses in the preceding 3-min period. If, for a given animal, the average suppression ratio over several days was less than .1 for either punishment or conditioned suppression components, the shock level was decreased; if it exceeded .3, the shock level was increased. Adjustments of this kind were made if necessary every 7-10 days. For the purpose of data analysis, sessions in Phase 2 were grouped into blocks of four. Analyses conducted in order to determine whether the lesions differentially affected response suppression elicited by $S_{c}$ and $S_{p}$ have been presented elsewhere (Feldon, Rawlins, \& Gray, in press).

\section{Data Analysis}

For each subject in each session, eight response rate scores were collected for analysis. They were: responses/minute in the two punishment intrusion periods, and the 3 -min periods preceding them, and responses/minute in the two conditioned suppression intrusion periods, and the 3 -min periods preceding them. For the analyses, the scores were transformed logarithmically to achieve homogeneity of variance.

The preintrusion period scores were used as a measure of baseline response rates. The intrusion period scores were submitted to an analysis of variance, comparing the different groups of rats according to lesion condition. Analyses of covariance were also car- 
ried out, to allow for any uncontrolled variation in the baseline response rates before each intrusion period, and for differences in baseline rates produced by the lesions: in these analyses, the scores from the intrusion periods provided the variates, with the corresponding scores from the immediately preceding period providing the covariates (Rawlins et al., 1980). Where the covariance regression was significant, the appropriately adjusted scores are reported; in all other cases, the unadjusted response rates from the analysis of variance are given.

Both in the analyses of variance and the analyses of covariance, differences in trend were estimated by the method of orthogonal polynomials; the analyses also provided the error terms for reported $t$ tests. To assist in interpreting the analyses, in addition to conducting a combined analysis of all lesion conditions, we compared each lesion condition separately to the OC group.
Finally, the shock levels required to keep the animals within the desired range of suppression ratios in Phase 2 (see Procedure) were submitted to a further analysis of variance comparing the different lesion conditions. This determined whether different shock intensities were required to maintain a given suppression ratio in the different lesion groups.

\section{RESULTS}

\section{Histology and Electrophysiology}

Examples of hippocampal electrical activity before and after the lesions were made in animals from each group are shown in Figure 1. Reconstructions of the

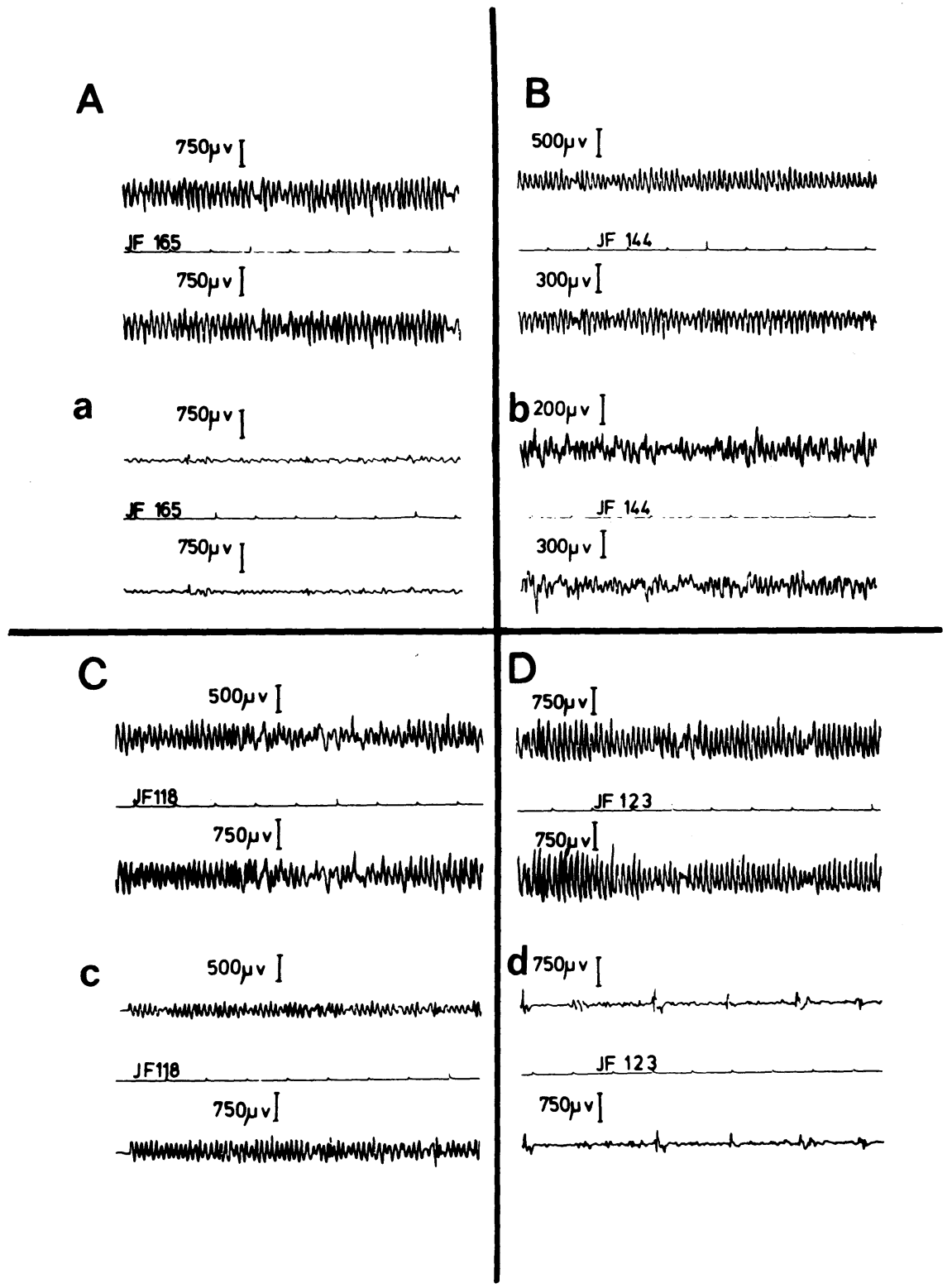

Figure 1. Recordings of hippocampal electrical activity in individual rats before (uppercase letters) and after (lowercase letters) lesions to the septal area. Each set of three tracings shows activity from left and right hippocampi and time in seconds; the animal number is indicated above the time marker. Panels $A$ and $B$ show successful and failed medial septal lesions, respectively; panels $C$ and $D$ show successful and failed lateral septal lesions. Filter settings: $<1$ and $>75 \mathbf{H z}$. 

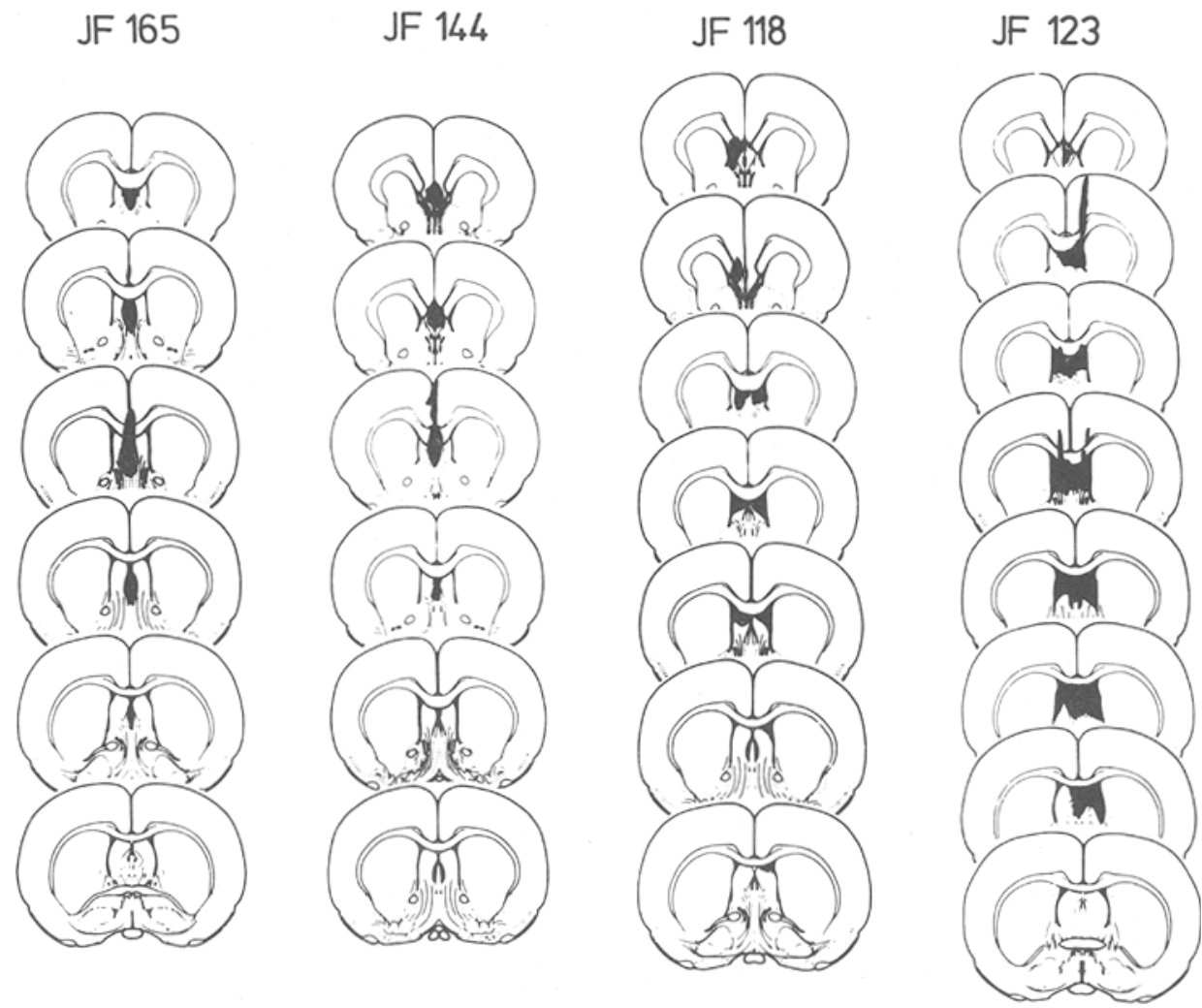

Figure 2. Reconstructions of lesions (shaded black) in the four rats whose hippocampal electrical activity is shown in Figure 1. JF 165 and JF 144 were classified as successful and failed medial septal lesions, respectively; JF 118 and JF 123, were classified as successful and failed lateral septal lesions. The reconstructions are shown on plates from the König and Klippel (1963) atlas.

damage in one subject from each of the four lesion conditions are presented in Figure 2. One intended LS rat proved to have no damage to the septal area, so its results were discarded. The remaining LS and all the MS brains were judged to have sustained acceptable lesions; they are described more fully by Rawlins et al. (1979). The FL subjects had extensive damage to both the lateral and the medial septal areas; the FM subjects had damage to the dorsomedial zone of the lateral septal nuclei, or unilateral lateral septal damage, or some degree of both. The OC subjects had no damage to the septal area other than the electrode tracts.

\section{Behavioral Results}

During the last 10 days of RI training before shock was introduced in Phase 1 of the experiment, there were significant differences in mean response rates between the five lesion groups $[F(4,212)=55.59$, $p<.001]$. Further analysis by $t$ tests showed that the MS group responded significantly more, and the FM group significantly less, than controls $(p<.001$ in both cases); neither the LS nor the FL group differed significantly from controls. Mean rates- $\log _{10}[($ responses/min) +1$]$-for the five groups were: OC, 1.75; MS, 1.91; LS, 1.77; FM, 1.62; FL, 1.75; standard errors .016-.023, depending on $n$.

\section{Phase 1}

Baseline rates. There were no differences in baseline rates between the OC, LS, and FM groups. However, rates were significantly greater in MS rats than in the operated controls (top panel of Figure 3): main effect of lesion in the MS vs. OC comparison, $F(1,13)$ $=8.87, \mathrm{p}<.05$; lesion $\times$ session interaction, $\mathrm{F}(22,585)$ $=1.76, p<.05$. A similar effect emerged from the comparison of the FL and OC groups [lesion $\times$ session interaction, $F(22,450)=1.65, p<.05$; Figure 4]. Whereas rates in the OC group gradually fell as Phase 1 proceeded and shock intensity increased (presumably reflecting generalization of suppression from shock periods to baseline responding), this did not occur in either lesion group (Figures 3 and 4).

Response suppression. Interpretation of the effects of the lesions on response rates during the intrusion periods is complicated by the need to take account of lesion-produced changes in baseline rates in the MS and FL groups. Both these groups had a higher 


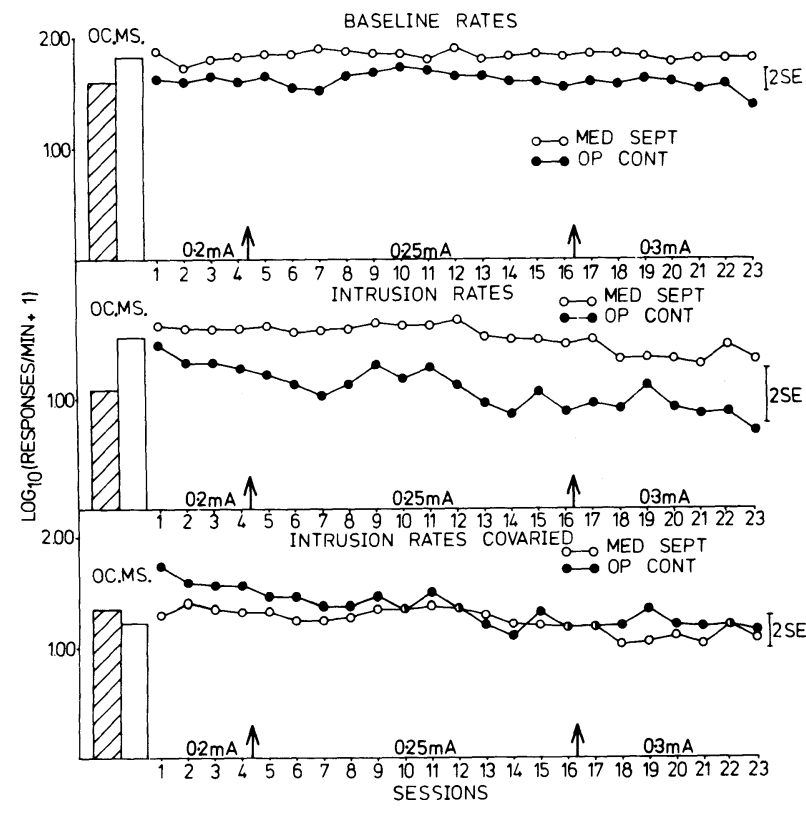

Figure 3. Response rates in the operated control $(\mathrm{OC})$ and medial septal (MS) groups for each session of Phase 1. Histograms to the left show mean rates throughout Phase 1. Bar markers to the right show two standard errors (SE) based on the lesion $X$ session interactions from the analysis of variance or covariance. Shock levels and the times of change of shock levels (arrows) are shown at the bottom of each panel. The top panel shows baseline rates; the middle panel shows rates during intrusion periods, averaged over punishment and conditioned suppression; and the bottom panel shows the effect on intrusion rates of covarying baseline rates. Note that covariance results in changed scores in the control group, and that the change depends on the particular experimental group with which the control group is compared.

baseline response rate than the $\mathrm{OC}$ group in the unadjusted analysis of variance. The consequences of adjusting for these baseline changes by the covariance analysis are illustrated in Figure 3 for the MS condition. The uncovaried data demonstrated that the controls became increasingly more suppressed than the MS group as the experiment progressed and the shock level was increased [linear component of the lesion $\times$ session interaction in the analysis of variance, $F(1,585)=8.82, p<.01$; middle panel of Figure 3]. However, in the analysis of covariance this apparent increase in resistance to shock-induced suppression was eliminated, and in the early sessions of Phase 1 the trend was even reversed [lesion $\times$ session, $F(22,584)=1.69, p<.05$; bottom panel of Figure 3]. There was thus no evidence for alleviation of response suppression in the MS group once the lesioninduced increase in baseline response rates was allowed for.

The pattern of results in the analyses of variance and covariance comparing the FL and $\mathrm{OC}$ groups was similar; covariance reduced the extent of lesioninduced disinhibition, but in this case did not elimate it [lesion $\times$ session, $F(22,499)=2.32, \mathrm{p}<.01$; Fig- ure 4]. Thus, the FL group showed an increase in resistance to shock-induced suppression even after allowing for the lesion-induced increase in baseline response rates.

In the LS and FM groups, in which baseline response rates were not affected by the lesions, there was clear and straightforward evidence for disinhibition of responding during shock periods (Figure 5). In the LS vs. OC covariance analysis, both the main effect of lesion $[F(1,11)=6.52, p<.05]$ and the lesion $\times$ session interaction $[F(22,539)=2.14$, $\mathrm{p}<.01]$ were significant; and in the FM vs. OC analysis, there was a significant linear component in the lesion $\times$ session interaction $[F(1,449)=6.97$, $\mathrm{p}<.011$. In both cases, the interaction reflected the fact that, relative to the two lesion groups, rates became steadily more suppressed in the controls as Phase 1 proceeded.

In the three groups in which the lesions produced response disinhibition there was no evidence that this depended on the presence, or absence, of a response contingency (see Table 1).

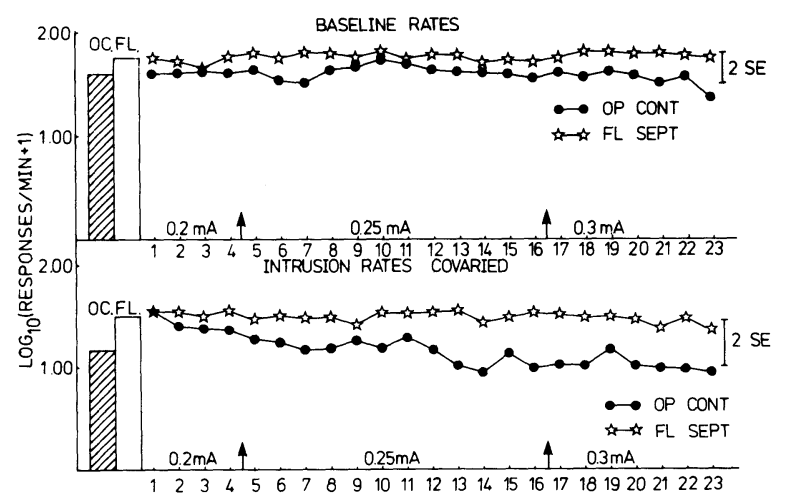

Figure 4. Response rates during Phase 1 in the operated control (OC) and failed lateral (FL) septal groups. Conventions as in Figure 3 , top and bottom panels.

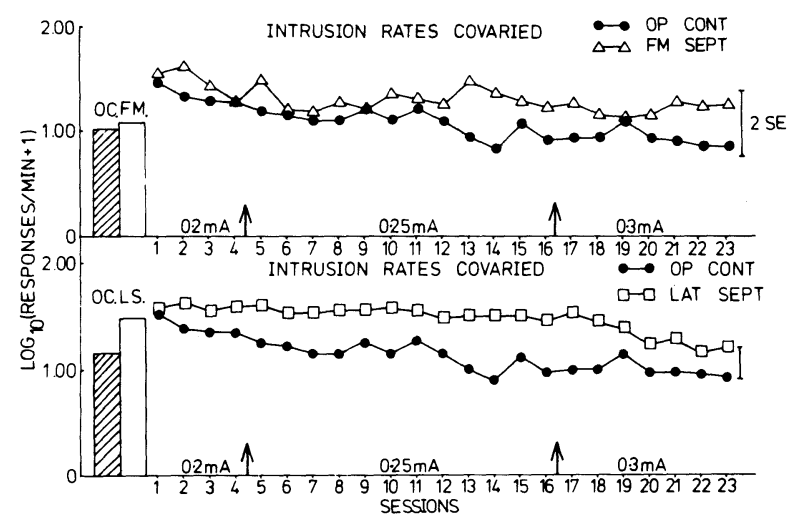

Figure 5. Response rates during Phase 1 in the operated control (OC) and failed medial (FM) septal groups (top panel) and in the OC and lateral septal (LS) groups (bottom panel). Conventions as In Figure 3, bottom panel. 
Table 1

Mean Difference in Covaried Log-Transformed Responses per Minute Between OC and LS, FM, and FL

\begin{tabular}{|c|c|c|c|c|c|c|}
\hline & \multicolumn{2}{|c|}{ LS } & \multicolumn{2}{|c|}{ FM } & \multicolumn{2}{|c|}{$\mathrm{FL}$} \\
\hline & Mean & SE & Mean & SE & Mean & SE \\
\hline Punishment & .35 & .13 & .27 & .25 & .36 & .17 \\
\hline Conditioned Suppression & .31 & .13 & .17 & .25 & .30 & .17 \\
\hline
\end{tabular}

Note-SE = standard error appropriate to Lesion by Contingency interaction.

\section{Phase 2}

Since there was loss of data in some cases, the analyses were based on the minimum number of blocks of sessions for which there were complete data for all subjects, that is, 22 blocks ( 88 sessions).

Baseline rates. The MS group continued to show higher baseline rates than did controls $[F(1,13)=$ $7.93, p<.05]$. No other groups differed from controls.

Response suppression. The method of adjusting shock for individual animals to produce similar suppression ratios achieved its purpose. No lesion group differed significantly from controls in mean response rates during the intrusion periods as tested by the analyses of covariance. The mean intensities of shock delivered to the different groups over the whole of Phase 2 were (in $\mathrm{mA}$ ): OC, .35; MS, .42; LS, .47; FM, .49; and FL, .53. The analysis of variance of the shock intensities revealed a significant effect of lesion $[F(4,24)=8.37, p<.001]$. When differences between the means were tested by Scheffé contrasts, all lesion groups except MS had significantly higher shock levels than controls and the FL group had a significantly higher shock level than the MS group (minimum $\mathrm{p}<.05$ ).

\section{DISCUSSION}

The results permit the following conclusions: (1) medial, but not lateral, septal lesions increased baseline responding; (2) lateral, but probably not medial, septal lesions disinhibited responding suppressed by signaled shock, whether or not the shock was response-contingent; and (3) the differential behavioral effects of medial and lateral septal lesions were closely related to their effects on the hippocampal theta rhythm.

There are several previous reports that large lesions of the anterior septal area elevate responding on variable-interval schedules in the Skinner box (e.g., Atnip \& Hothersall, 1975; Dickinson, 1973). Our results demonstrate that this effect is due to damage to the medial septal area (eliminating hippocampal theta) only. Elevated baseline responding was seen in the MS and FL groups, especially the former. These groups had in common damage to the medial septal area and loss of the hippocampal theta rhythm. No change occurred in baseline responding in the LS group, while in the FM group baseline rates prior to the introduction of shock in Phase 1 were actually lower than those seen in the operated controls; in both these groups, the medial septal area and the theta rhythm were relatively intact.

The higher baseline rates seen in the MS group apparently reflect two different tendencies. First, the MS lesion increased RI rates as such, since this was elevated before shock was introduced in Phase 1 . Second, this lesion eliminated the tendency, seen in the operated controls during Phase 1, for suppression of responding to generalize from shock periods to baseline rates (Figure 3). The FL group differed from the MS group in that they did not show elevated baseline response rates before the introduction of shock in Phase 1. They resembled the MS group in showing elevated rates in Phase 1 itself. The elevation can again be best attributed to smaller generalized baseline suppression than that seen in the controls (Figure 4).

Our findings confirm previous reports that the locus of the disinhibitory effect of septal lesions on behavior suppression by the threat of shock lies in the lateral septal region (Hamilton et al., 1970; McGowan et al., 1972). Both the LS group and the FM group, in which the medial septal area and the theta rhythm were essentially intact, showed disinhibition of responding in the shock periods in Phase 1. In neither case could this have been due to changes in baseline responding. The MS and FL groups, which both had a loss of the theta rhythm, also showed elevated responding during shock periods in Phase 1, but both these groups showed in addition increased baseline response rates. The analyses of covariance showed that the apparent disinhibition seen in the MS group could be attributed to this increase in baseline response rates. However, significant disinhibition remained after covariance in the FL group, showing that increased baseline response rates could not account for the increased response rate in the shock periods. Since the FL group had sustained damage to both the medial and the lateral septal areas, there is no evidence that damage to the medial septal area alone can disinhibit suppressed responding. The results of Phase 2, in which response suppression was held constant between the different lesion conditions and shock intensity was varied, lead to the same conclusions. Significantly higher shock intensities were required to produce equivalent degrees of response suppression in the LS, FM, and FL groups relative to controls. Although a higher shock intensity was also required in the MS group (.42 vs. $.35 \mathrm{~mA}$ ), this difference did not quite attain acceptable levels of significance. Thus, our results indicate that damage to the medial septal area has, at best, 
only a slight effect on the suppression of responding by shock, again in agreement with Hamilton et al. (1970) and McGowan et al. (1972).

These effects of septal lesions were obtained whether or not shock delivery was contingent upon leverpressing. Thus, our results, obtained in a withinsubject design, confirm Dickinson's (1975) report of equal alleviation of response suppression after unselective septal lesions in different groups of animals exposed either to response-contingent or responseindependent shock.

Several aspects of the results support the view that the behavioral effects of discrete lesions within the septal area are related to the changes such lesions produce in hippocampal electrical activity (Donovick, 1968). First, the MS and LS categories, primarily defined by electrophysiological criteria, gave rise to two behavioral double dissociations: they differed in their effects on baseline responding and in their effects on response suppression during the intrusion periods. Second, the "failed"' lesions, again defined electrophysiologically, produced behavioral results that tended to resemble those of the other lesion (MS or LS) which had the same influence on the hippocampal theta rhythm. Thus, the FM group resembled the LS group, not only in having an intact theta rhythm, but also in that baseline responding was unaffected by the lesion, while response suppression was disinhibited. The FL group showed elements of both MS and LS effects. As in the MS group, which also had an abolition of theta rhythm, the FL group showed increased baseline responding; as in the LS group, which had in common dorsolateral septal damage, the FL group showed decreased response suppression.

These findings complement other experiments which have shown double dissociations between the effects of MS and LS lesions on quite different forms of behavior. Feldon and Gray (1979a, 1979b) studied the partial reinforcement extinction effect (PREE) in the straight alley. In this design, one group of animals is trained with food reward on every trial (continuous reinforcement) and a second with reward on a random $50 \%$ of trials (partial reinforcement). In normal animals, the partially reinforced group is subsequently more resistant to extinction than the continuously reinforced group. LS, but not MS, lesions blocked the partial reinforcement extinction effect; and MS, but not LS, lesions, increased resistance to extinction after either type of training. The latter finding confirmed other suggestions that the increased resistance to extinction which results from large lesions in the septal area is due specifically to medial septal damage (Donovick, 1968; Grossman, 1976). However, both in the present experiment and in those of Hamilton et al. (1970) and McGowan et al. (1972) it was damage to the lateral, not the medial, septal area which alleviated the response suppression caused by punishment.

These results with selective lesions pose problems for the hypothesis that the response suppression caused by punishment and that caused by frustrative nonreward are mediated by common mechanisms (Gray, 1967; Wagner, 1966). This hypothesis is supported by considerable behavioral (Gray, 1975) and psychopharmacological (Gray, 1977) data. It is also supported by the results of experiments in which large septal (Dickinson, 1974; Lubar \& Numan, 1973) or hippocampal lesions (Altman, Brunner, \& Bayer, 1973) have been studied. Thus, when large, unselective lesions have been used, they have been shown to disinhibit the response suppression produced either by nonreward or by shock. However, the results of the present experiment combined with the previous findings cited above suggest that LS lesions alleviate the suppression produced by shock but not by nonreward; conversely, MS lesions alleviate nonreward but not shock-induced suppression. Thus, there appears to be important functional specialization within the septum, and studies with large lesions have apparently been looking at the combined consequences of damaging these specialized areas, as in our FL group. A similar double dissociation has been reported between the effects of certain adrenopituitary hormones on responses to nonreward and punishment (Gray \& Garrud, 1977). Nonetheless, it is still too early to reject the hypothesis of a single physiological system mediating the response suppression produced by punishment and nonreward (Gray, 1967). To do this, it will be necessary to conduct experiments in which everything other than the punishment/nonreward dichotomy is held as constant as possible. However, it is clear that the evidence against a single mechanism for response inhibition is gaining in strength.

\section{REFERENCES}

Altman, J., Brunner, R. L., \& Bayer, S. A. The hippocampus and behavioral maturation. Behavioral Biology, 1973, 8, 557-596.

Apostol, G., \& CreutzFeldt, O. D. Crosscorrelation between the activity of septal units and hippocampal EEG during arousal. Brain Research, 1974, 67, 65-75.

AtNip, G., \& Hothersall, D. Response suppression in normal and septal rats. Physiology \& Behavior, 1975, 15, 417-421.

Brady, J. V., \& NaUta, W. J. H. Subcortical mechanisms in emotional behavior: The duration of affective changes following septal and habenular lesions in the albino rat. Journal of Comparative and Physiological Psychology, 1955, 48, 412-420.

Dickinson, A. Septal lesions in rats and the acquisition of freeoperant successive discriminations. Physiology \& Behavior, 1973, 10, 305-313.

Dickinson, A. Response suppression and facilitation by aversive stimuli following septal lesions in rats: A review and model. Physiological Psychology, 1974, 2, 444-456.

Dickinson, A. Suppressive and enhancing effects of footshock on food-reinforced operant responding following septal lesions in 
rats. Journal of Comparative and Physiological Psychology, 1975, 88, 851-861.

Donovick, P. J. Effects of localized septal lesions on hippocampal EEG activity and behavior in rats. Journal of Comparative and Physiological Psychology, 1968, 66, 569-578.

Duncan, P. M. Effect of septal area damage and base-line activity levels on conditioned heart-rate response in rats. Journal of Comparative and Physiological Psychology, 1972, 81, 131-142.

Feldon, J., \& Gray, J. A. Effects of medial and lateral septal lesions on the partial reinforcement extinction effect at one trial a day. Quarterly Journal of Experimental Psychology, 1979, 31, 653-674. (a)

Feldon, J., \& Gray, J. A. Effects of medial and lateral septal lesions on the partial reinforcement extinction effect at short inter-trial intervals. Quarterly Journal of Experimental Psychology, 1979, 31, 675-690. (b)

Feldon, J., Rawlins, J. N. P., \& Gray, J. A. Discrimination of response-contingent and response-independent shock by rats: Effects of medial and lateral septal lesions and chlordiazepoxide. Behavioral and Neural Biology, in press.

Gray, J. A. Disappointment and drugs in the rat. Advancement of Science, 1967, 23, 595-605.

GrAY, J. A. Elements of a two-process theory of learning. London: Academic Press, 1975.

Gray, J. A. Drug effects on fear and frustration: Possible limbic sites of action of minor tranquilizers. In L. L. Iversen, S. D. Iversen, \& S. H. Snyder (Eds.), Handbook of psychopharmacology (Vol. 8). New York: Plenum Press, 1977.

Gray, J. A., \& Garrud, P. Adreno-pituitary hormones and frustrative nonreward. In L. H. Miller, C. A. Sandman, \& A. B. Kastin (Eds.), Neuropeptide influences on the brain and behavior: Advances in biochemical psychopharmacology (Vol. 17). New York: Raven Press, 1977.

Grossman, S. P. Behavioral functions of the septum: A reanalysis. In J. De France (Ed.), The septal nuclei. New York: Plenum Press, 1976.

Hamilton, L. W., Kelsey, J. E., \& Grossman, S. P. Variations in behavioral inhibition following different septal lesions in rats. Journal of Comparative and Physiological Psychology, 1970, 70, 79-86.

Harvey, J. A., Lints, C. E., Jacobson, L. W., \& Hunt, H. F. Effects of lesions in the septal area on conditioned fear and discriminated instrumental punishment in the albino rat. Journal of Comparative and Physiological Psychology, 1965, 59, 37-48.
James, D. T. D., McNaughton, N., Rawlins, J. N. P., Feldon, J., \& GraY, J. A. Septal driving of hippocampal theta rhythm as a function of frequency in the free-moving male rat. Neuroscience, 1977, 2, 1007-1017.

KöNIG, J. F. R., \& KLIPPEL, R. A. The rat brain. Baltimore, Md: Williams \& Wilkins, 1963.

Lubar, J. F., \& Numan, R. Behavioral and physiological studies of septal functions and related medial cortical structures. Behavioral Biology, 1973, 8, 1-25.

McGowan, B. K., Hankins, W. G., \& Garcia, J. Limbic lesions and control of the internal and external environment. Behavioral Biology, 1972, 7, 841-852.

Millenson, J. R. A general language for on-line control of psychological experimentation. Behavioural Sciences, 1971, 16, 248-256.

Molino, A. Sparing of function after infant lesions of selected limbic structures in the rat. Journal of Comparative and Physiological Psychology, 1975, 89, 868-881.

O'KeEFe, J., \& BlaCK, A. H. Single unit and lesion experiments on the sensory inputs to the hippocampal cognitive map. In K. Elliott \& J. Whelan (Eds.), Functions of the septo-hippocampal system (CIBA Foundation Symposium 58, new series). Amsterdam: Elsevier, 1978.

Rawlins, J. N. P., Feldon, J., \& Gray, J. A. Septo-hippocampal connections and the hippocampal theta rhythm. Experimental Brain Research, 1979, 37, 49-63.

Rawlins, J. N. P., Feldon, J., \& Gray, J. A. Discrimination of response-contingent and response-independent shock by rats: Effects of chlordiazepoxide $\mathrm{HCl}$ and sodium amylobarbitone. Quarterly Journal of Experimental Psychology, 1980, 32, 215-232.

STUMPF, Ch. Drug action on the electrical activity of the hippocampus. International Review of Neurobiology, 1965, 8, 77-138.

WAgNe R, A. R. Frustration and punishment. In R. M. Haber (Ed.), Current research on motivation. New York: Holt, Rinehart \& Winston, 1966.

Winson, J. Loss of hippocampal theta rhythm results in spatial memory deficit in the rat. Science, 1978, 201, 160-163.

(Manuscript received July 24, 1981; revision accepted for publication September 28, 1981.) 